\title{
Reclassification of [Pasteurella] trehalosi as Bibersteinia trehalosi gen. nov., comb. nov.
}

Correspondence

P. J. Blackall

pat.blackall@dpi.qld.gov.au
[Pasteurella] trehalosi is an important pathogen of sheep being primarily associated with serious systemic infections in lambs, but also having an association with pneumonia in sheep (Gilmour \& Gilmour, 1989). The organism, first described as a separate species by Sneath \& Stevens (1990), was part of the complex of species once known as the '[Pasteurella] haemolytica' complex (Angen et al., 1999). The '[Pasteurella] haemolytica' complex, which consisted of

Abbreviations: AFLP, amplified fragment length polymorphism; LPS, lipopolysaccharide; MLEE, multilocus enzyme electrophoresis; OMP, outer membrane protein.

The GenBank/EMBL/DDBJ accession numbers for the 16S rRNA gene sequences of strains B464/94 and C1008-I are DQ361040 and D0361041, respectively. biovars A and T (Smith, 1959), has been extensively reorganized. The organisms once assigned to the $\mathrm{T}$ biovar were named [Pasteurella] trehalosi (Sneath \& Stevens, 1990). However, there is clear evidence that the species is not closely affiliated with Pasteurella multocida, the type species of the genus Pasteurella (Angen et al., 1999). A new genus, Mannheimia, houses the A biovar organisms from the old 'Pasteurella] haemolytica' complex with five species: Mannheimia haemolytica, Mannheimia glucosida, Mannheimia granulomatis, Mannheimia ruminalis and Mannheimia varigena (Angen et al., 1999), as well as currently un-named taxa such as Bisgaard Taxon 39 (Blackall et al., 2001).

There is evidence of diversity within the species [P.] trehalosi. A serotyping scheme based on capsular polysaccharides, 
originally developed by Biberstein et al. (1960) which recognizes four serovars, termed T3, T4, T10 and T15, has been used to study strain variation (Adlam, 1989; Gilmour \& Gilmour, 1989). Davies \& Quirie (1996) found six lipopolysaccharide (LPS) types and four outer membrane protein (OMP) types in a collection of 60 isolates mainly from sheep in the UK and noted that this represented only a limited degree of diversity. Using multi-locus enzyme electrophoresis (MLEE), Davies et al. (1997) concluded that the degree of diversity within the same 60 isolates studied by LPS and OMP typing (Davies \& Quirie, 1996) was lower than that of most other pathogenic species that had been studied by MLEE. In the present investigation, we have characterized a broad collection of strains tentatively identified as [P.] trehalosi to gain some insight into the diversity present in the taxon. We have then used the results of the current study and past studies to reclassify and rename this taxon. The reclassification will facilitate the study of the pathogenesis and epidemiology of this important veterinary organism.

The isolates and strains used in this study were obtained from the culture collection of the Department of Veterinary Pathobiology, The Royal Veterinary and Agricultural University, Denmark, and are shown in Table 1. The type strain of $[P$.$] trehalosi, strain NCTC 10370^{\mathrm{T}}$, was included along with 45 field isolates. The isolates were obtained from sheep (22 isolates), cattle (17 isolates), goats (1 isolate) and roe deer ( 3 isolates), while the source of three reference serovars $(\mathrm{FT} 3, \mathrm{~T} 3 \mathrm{H}$ and $\mathrm{T} 10 \mathrm{H})$ remain unknown.

All of the isolates and the type strain were characterized as described previously (Bisgaard et al., 1991). The CAMP reaction of all of the isolates was determined as previously described (Christie et al., 1944). In addition, a specific PCR for the leukotoxin of $[P$.] trehalosi (Green et al., 1999) was performed on a subset of the isolates.

Amplified fragment length polymorphism (AFLP) typing was carried out as reported previously (Christensen et al., 2003a). Briefly, the non-selective BglII primer (FAM-5' GAGTACACTGTCGATCT 3') and the non-selective BspDI primer (5' GTGTACTCTAGTCCGAT $3^{\prime}$ ) were used to amplify the fragments following restriction digestion and ligation to their corresponding adaptors. All AFLP reactions were carried out twice to determine the reproducibility of the method. Amplification products were detected on an automated DNA sequencer (ABI 377; PE Biosystems). Each lane included an internal lane size standard labelled with ROX dye (Applied Biosystems) and GeneScan 3.1 fragment analysis software (Applied Biosystems) was used for fragment size determination and pattern analysis. AFLP profiles comprising fragments in the size range $50-500 \mathrm{bp}$ were considered for numerical analysis with the program GelCompar II (Applied Maths). Normalized AFLP fingerprints were compared using the Dice similarity coefficient and clustering analysis was performed by the unweighted pair group method with arithmetic means (UPGMA).
16S rRNA gene sequencing of strains B464/94 and C1008-I was performed as described below. Bacteria were cultured overnight in brain heart infusion broth (Difco) and DNA was extracted, with enzymic treatments with lysozyme and proteinase $\mathrm{K}$ as previously reported (Leisner et al., 1999). PCR amplification was performed according to the standard conditions described by Vogel et al. (1997). Oligonucleotides for both PCR amplification and sequencing were synthesized according to sequences and 16S rRNA positions given in Dewhirst et al. (1989) and Paster \& Dewhirst (1988). DNA sequencing was performed on a DNA sequencer (ABI 377; Applied Biosystems) with unlabelled primers and the BigDye kit according to protocols described with the Automated DNA Sequencing Chemistry Guide (Applied Biosystems, 2000). Searches for DNA sequences at NCBI (Benson et al., 2004; www.ncbi.nih.nlm.gov) were performed by BLAST (Altschul et al., 1997).

In addition to the two sequences determined in the present study, GenBank was searched for available 16S rRNA gene sequences of other strains of $[P$.] trehalosi. Sequences were found for the following five strains: NCTC $10370^{\mathrm{T}}$, NCTC 10641, NCTC 11550, NCTC 10624 and NCTC 10626 with GenBank accession nos AY362927, U57074, U57073, M75063 and U57075, respectively. The sequences for the type strains of the type species of the currently recognized genera within the family Pasteurellaceae were also obtained. Pairwise comparisons for similarity were performed by EMBOSS (Rice et al., 2000). Sequences were aligned by CLUSTAL_X (Thompson et al., 1997).

Maximum-likelihood analysis was performed by fastDNAml including bootstrap analysis (Olsen et al., 1994) run on a Linux compatible server. The transition/transversion ratio was set to 1.5 . The region corresponding to Escherichia coli positions 87-1392 of the $\mathrm{rrnB}$ gene was used after removal of gaps with 226 distinct data patterns analysed. The 'loop' script provided by fastDNAml was used to justify that the tree with maximum $\ln L$ had been found.

By phenotypic testing, 43 isolates were identified as $[P$.] trehalosi. These 43 isolates were Gram-negative, non-motile (at 22 and $37^{\circ} \mathrm{C}$ ) rods that were fermentative in the Hugh and Leifson test. The isolates did not show symbiotic growth on blood agar and gave positive results in the porphyrin, phosphatase and alanine aminopeptidase tests. All isolates were positive in the nitrate reduction test and were negative in Simmons' citrate, methyl red and Voges-Proskauer tests. No isolate produced $\mathrm{H}_{2} \mathrm{~S}$, urease or gelatinase. Indole was not produced and Tweens 20 and 80 were not hydrolysed. The isolates were all negative in the arginine dehydrolase and lysine- and ornithine decarboxylase tests. Phenylalanine was not deaminated, acid was not produced from mucate and alkali was not produced in the malonate test. No isolate could grow in $\mathrm{KCN}$. The isolates showed variable reactions in the catalase and oxidase tests. Variable results were obtained for haemolysis (on bovine blood agar), in the CAMP test (performed using bovine blood cells) and for the ability to grow on MacConkey agar. Over half of the isolates 
Table 1. Isolates used in this study

ND, No data; NT, no serotype; B, Belgium; DK, Denmark; S, Sweden; UK, United Kingdom.

\begin{tabular}{|c|c|c|c|c|c|}
\hline Isolate & $\begin{array}{c}\text { Host } \\
\text { species }\end{array}$ & Serovar & $\begin{array}{l}\text { Disease association/ } \\
\text { Isolation site }\end{array}$ & Country & $\begin{array}{c}\text { AFLP } \\
\text { cluster/Type }\end{array}$ \\
\hline $34876 / 76$ & Bovine & NT & Lung & UK & $1 / \mathrm{A}$ \\
\hline $34880 / 76$ & Bovine & NT & Lung & UK & $1 / \mathrm{A}$ \\
\hline NCTC 10371 & Lamb & 15 & Septicaemia & UK & $1 / \mathrm{B}$ \\
\hline NCTC 10624 & Ovine & 15 & Nasopharyngeal mucus & UK & $1 / \mathrm{B}$ \\
\hline 4935/S945T3 & Ovine & 3 & Disease & UK & $1 / \mathrm{B}$ \\
\hline T34682 & Ovine & 3 & Disease & UK & $1 / \mathrm{B}$ \\
\hline S487/T3 & Ovine & 3 & Disease & UK & $1 / \mathrm{B}$ \\
\hline T15T700B & Ovine & 15 & Septicaemia & UK & $1 / \mathrm{B}$ \\
\hline NCTC $10370^{\mathrm{T}}$ & Ovine & 15 & Septicaemia & UK & $1 / \mathrm{B}$ \\
\hline $51810 / 78$ & Ovine & NT & Septicaemia & UK & $1 / \mathrm{B}$ \\
\hline $\mathrm{T} 4 \mathrm{H}$ & Ovine & 4 & Septicaemia & UK & $1 / \mathrm{C}$ \\
\hline X801 & Ovine & NT & Disease & UK & $1 / \mathrm{C}$ \\
\hline T4T740C & Ovine & 4 & Septicaemia & UK & $1 / \mathrm{C}$ \\
\hline FT4 & Ovine & 4 & Septicaemia & UK & $1 / \mathrm{C}$ \\
\hline FT3 & ND & 3 & ND & UK & $1 / \mathrm{D}$ \\
\hline $\mathrm{T} 3 \mathrm{H}$ & ND & 3 & Same source as FT3 & UK & $1 / \mathrm{D}$ \\
\hline T3T631 & Ovine & 3 & Septicaemia & UK & $1 / \mathrm{D}$ \\
\hline NCTC 10369 & Ovine & 4 & Septicaemia & UK & $1 / \mathrm{E}$ \\
\hline $\mathrm{T} 10 \mathrm{H}$ & ND & 10 & $\mathrm{ND}$ & UK & $1 / \mathrm{E}$ \\
\hline T10T676A & Ovine & 10 & Septicaemia & UK & $1 / F$ \\
\hline $5083 / \mathrm{S} 261-1 \mathrm{~T}$ & Ovine & NT & Disease & UK & $1 / F$ \\
\hline 35 & Roe deer & NT & Brain & B & $1 / F$ \\
\hline 4674/S96/9-T & Ovine & NT & Disease & UK & $2 / \mathrm{G}$ \\
\hline P32 & Caprine & NT & $\mathrm{ND}$ & B & $2 / \mathrm{H}$ \\
\hline C1019-II & Bovine & NT & Granuloma & DK & $3 / \mathrm{I}$ \\
\hline 83 & Bovine & NT & Intestine & B & $3 / \mathrm{J}$ \\
\hline 4721 & Ovine & NT & Disease & UK & $4 / \mathrm{K}$ \\
\hline $5083 / \mathrm{S} 261-2$ & Ovine & NT & Disease & UK & $4 / \mathrm{K}$ \\
\hline 4954/T3 & Ovine & 3 & Disease & UK & $4 / \mathrm{K}$ \\
\hline T10/S790 & Ovine & 15 & Septicaemia & UK & $4 / \mathrm{K}$ \\
\hline $51809 / 78$ & Ovine & 10 & Septicaemia & UK & $4 / \mathrm{K}$ \\
\hline B96/54 & Bovine & NT & Lung & $\mathrm{B}$ & $5 / \mathrm{L}$ \\
\hline 42 & Bovine & NT & Lung & B & $5 / \mathrm{L}$ \\
\hline 33 & Bovine & NT & Lung & B & $5 / \mathrm{L}$ \\
\hline B96/19 & Bovine & NT & Lung & B & $5 / \mathrm{L}$ \\
\hline C857-II & Bovine & NT & Pharynx & DK & $5 / \mathrm{M}$ \\
\hline B464/94 & Roe deer & NT & Lung & S & $5 / \mathrm{N}$ \\
\hline B96/39 & Bovine & NT & Joint & B & $5 / \mathrm{O}$ \\
\hline H12 & Bovine & NT & Lung & B & $5 / \mathrm{P}$ \\
\hline $1009-1$ & Bovine & NT & Granuloma & DK & 6/Q \\
\hline B817/85 & Roe deer & NT & ND & S & 6/Q \\
\hline C1008-I & Bovine & NT & Granuloma & DK & $6 / \mathrm{R}$ \\
\hline $35 \mathrm{~B}$ & Bovine & NT & Lung & B & $6 / S$ \\
\hline $33 \mathrm{~B}^{*}$ & Bovine & NT & Intestine and lung & B & $7 / \mathrm{T}$ \\
\hline $28 \mathrm{~B} \dagger$ & Bovine & NT & Bronchial lavage & B & $8 / \mathrm{U}$ \\
\hline $42 \mathrm{~B} \ddagger$ & Bovine & NT & ND & B & $9 / \mathrm{V}$ \\
\hline
\end{tabular}

${ }^{\star} P$. multocida (ornithine- and indole-negative).

$\dagger$ Unclassified.

$\ddagger$. varigena. 
showed a yellowish pigment in colonies grown on blood agar. Acid was produced from (-)-D-ribose, (-)-Dmannitol, (-)-D-sorbitol, (-)-D-fructose, (+)-D-glucose, $(+)$-D-mannose, maltose, sucrose, $(+)$-D-trehalose and dextrin. Acid was not produced from myo-erythritol, adonitol, (+)-D-arabitol, xylitol, (+)-L-arabinose, (-)D-arabinose, (+)-D-xylose, (-)-L-xylose, dulcitol, (+)-Dfucose, (-)-L-fucose, (+)-D-galactose, $(+)$-L-rhamnose, $(-)$-L-sorbose, lactose, $(+)$-D-melibiose, $(+)$-D-melezitose, $(+)$-D-glycogen, inulin or $(+)$-D-turanose. The isolates varied in their ability to produce acid from glycerol, myo-inositol, cellobiose, raffinose, aesculin, amygdalin, arbutin, gentiobiose and salicin. All isolates were negative in the $\beta$-galactosidase (ONPG) test. All the isolates were negative in tests for $\alpha$-fucosidase, $\alpha$-galactosidase, $\alpha$-mannosidase and $\beta$-xylosidase. Variable results were obtained in the $\alpha$-glucosidase, $\beta$-glucosidase and $\beta$-glucuronidase tests. For characteristics showing variation, strain NCTC $10370^{\mathrm{T}}$ showed the following reactions: catalase- and oxidasenegative, weak haemolysis on bovine blood agar, CAMPpositive, weak growth on MacConkey agar, yellowish pigment, production of acid from cellobiose, raffinose, aesculin, amygdalin, arbutin, gentiobiose and salicin, but no acid produced from glycerol and myo-inositol. The $\beta$-glucosidase and $\alpha$-glucosidase tests were positive, while a $\beta$-glucuronidase test was negative. Seventeen out of 22 ovine isolates produced acid from all glycosides investigated, while only four out of fourteen bovine isolates had the capacity to produce acid from all glycosides.

A single bovine isolate (28 bronchial lavage), differing in ornithine decarboxylase activity and (+)-D-mannose fermentation, remained unidentified.

Of the two remaining bovine isolates included as blind controls in the AFLP characterization, one (isolate 33B) was identified as P. multocida (ornithine decarboxylase- and indole negative) and one (isolate 42B) was identified as M. varigena.

The PCR for the leukotoxin of [P.] trehalosi (Green et al., 1999) was used on ten CAMP-positive strains (NCTC 10369, NCTC $10370^{\mathrm{T}}$, NCTC 10371, NCTC 10624, FT3, T3H, 4935/S945T3, T34682, 4954/T3 and S487/T3) and gave a clear positive reaction for all ten isolates. When used on the six CAMP-negative isolates (C1008-I, C1019-II, B96/19, B96/39, B96/54 and B464/94), a suspect to weak-positive result was given with all six isolates.

The reproducibility of the AFLP method was evaluated by the analysis of duplicates of isolates with independently prepared templates, different selective PCR runs and different electrophoretic runs. The reproducibility of the method was good $(96.1 \%)$ with a standard deviation of $\pm 2.4 \%$. The clustering analysis is shown in Fig. 1. Field isolate C857-II was included as two separate cultures in the analysis. The two cultures of C857-II had an identical AFLP profile and were regarded as a single field isolate. All isolates used in the study shared at least $35 \%$ similarity in their AFLP profiles.
Indeed, all isolates, except for three isolates (numbers 33B, $28 \mathrm{~B}$ and $42 \mathrm{~B}$ ) shared at least $70 \%$ similarity in their profiles. As noted above, these three aberrant isolates represented P. multocida, an unclassified organism and M. varigena, respectively. For the purpose of this study, isolates with AFLP profiles of $\geqslant 90 \%$ similarity were defined as an AFLP type, while isolates with $\geqslant 80 \%$ similarity were defined as an AFLP cluster. As shown in Table 1, a total of 22 AFLP types (A to $\mathrm{V}$ ) were recognized and these types formed a total of nine AFLP clusters (1 to 9). AFLP types T, U and V (which corresponded to clusters 7, 8 and 9) consisted of the three strains known not to be representatives of $[P$.] trehalosi on the basis of phenotypic results. The exclusion of these strains from [P.] trehalosi was supported by the low similarity $(\leqslant 50 \%)$ of these strains with all other $[P$.] trehalosi isolates examined in the AFLP study.

Of the 22 AFLP types recognized, half were single isolate types. The largest AFLP type (type B) consisted of seven field isolates and the type strain (NCTC $10370^{\mathrm{T}}$ ), all of ovine origin. AFLP types $\mathrm{C}$ and $\mathrm{K}$ also only included ovine isolates. Only AFLP clusters $B$ and $C$ included strains producing acid from all of the glycosides investigated. The other large AFLP type was type $\mathrm{K}$ which contained five ovine field isolates that had an intermediate capacity to produce acid from glycosides. AFLP type B included serovars 3 and 15, while serovar 4 was associated with types $\mathrm{C}$ and $\mathrm{E}$ and serovar 10 with types E, F and K. However, serovar 3 was also associated with types $\mathrm{D}$ and $\mathrm{K}$.

Of the nine AFLP clusters recognized, six contained more than one isolate. AFLP cluster 1 was the largest cluster recognized and consisted of AFLP types A, B, C, D, E and F. AFLP cluster 1 included a total of 21 field isolates and the type strain NCTC $10370^{\mathrm{T}}$. The next largest cluster was cluster 5 which included eight isolates. Of the six multimember clusters, five were associated with a single host species. The only AFLP cluster that involved more than one host was cluster $\mathrm{F}$, where two isolates were of ovine origin and one isolate was of cervine origin.

In the $16 \mathrm{~S}$ rRNA gene sequence analysis, the major AFLP clusters were represented. To supplement the five strains already sequenced and representing all four serovars, two additional strains B464/94 and C1008-I were sequenced in the present study and deposited in GenBank with accession numbers DQ361040 and DQ361041, respectively. The lowest $16 \mathrm{~S}$ rRNA gene sequence similarity within $[P$.] trehalosi was $98.3 \%$ between strains NCTC 10624 and B464/ 94, isolated from sheep and roe deer, respectively. The highest similarity outside of $[P$.] trehalosi was $96.4 \%$ which was found between the type strain of $[P$.] trehalosi and the type strain of $M$. ruminalis.

The phylogenetic analysis showed that the strains of $[P$.] trehalosi formed a monophyletic group that was unrelated to other members of the Pasteurellaceae, including Mannheimia (Fig. 2). 


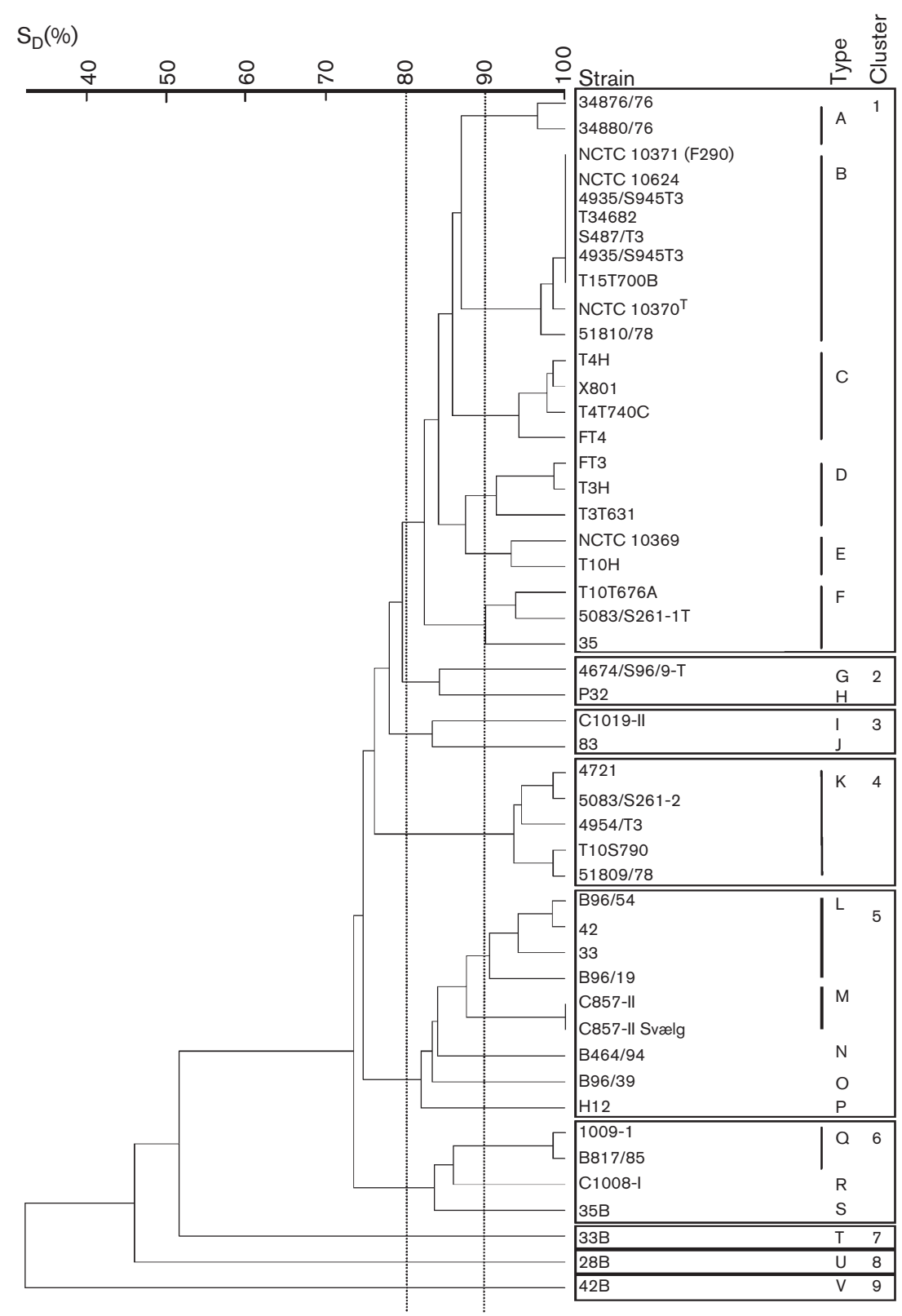

Fig. 1. Dendrogram (UPGMA) of AFLP similarities (Dice coefficient) between the strains of $[P$.$] trehalosi. \mathrm{S}_{\mathrm{D}}$, Dice similarity.
This study has confirmed earlier findings that [P.] trehalosi is a monophyletic group unrelated to other taxa within the family Pasteurellaceae. The full neighbour-joining tree of the family Pasteurellaceae constructed by Olsen et al. (2005) showed a deep branching of the type strain of [P.] trehalosi, unrelated to other members of the family. The deep branching was also found by Christensen et al. (2004c) with the application of maximum-likelihood analysis. Phylogenetic analysis based on 16S rRNA gene sequences has previously indicated that the four isolates of $[P$. trehalosi, representing the four recognized serovars within the taxon (T3, T4, T10 and T15), are closely related (showing at least $98.7 \%$ similarity) and form a monophyletic group (Davies et al., 1996). These 16S rRNA gene sequencebased results have been supported by phylogenies based on two housekeeping genes (Christensen et al., 2004c). In addition, only $62 \%$ or less DNA-DNA relatedness has been found between $[P$.] trehalosi and other members of the family Pasteurellaceae (Biberstein \& Francis, 1968; Mutters et al., 1985, 1986; Pohl, 1981). The uniqueness of [P.] trehalosi has also been demonstrated in terms of polyamine profiles (Busse et al., 1997). [P.] trehalosi strain NCTC 10624 (serovar T3) was not located on any of the seven rRNA branches outlined by De Ley et al. (1990). Indeed, this strain was located at the root of the large Haemophilus-PasteurellaActinobacillus rRNA branch (De Ley et al., 1990).

Hence, our study using 16S rRNA gene sequence analysis, AFLP typing and phenotypic characterization is in full accord with all existing evidence $-[P$.] trehalosi represents a distinct and separate genus within the family Pasteurellaceae. On the basis of our results, plus this existing evidence, we 


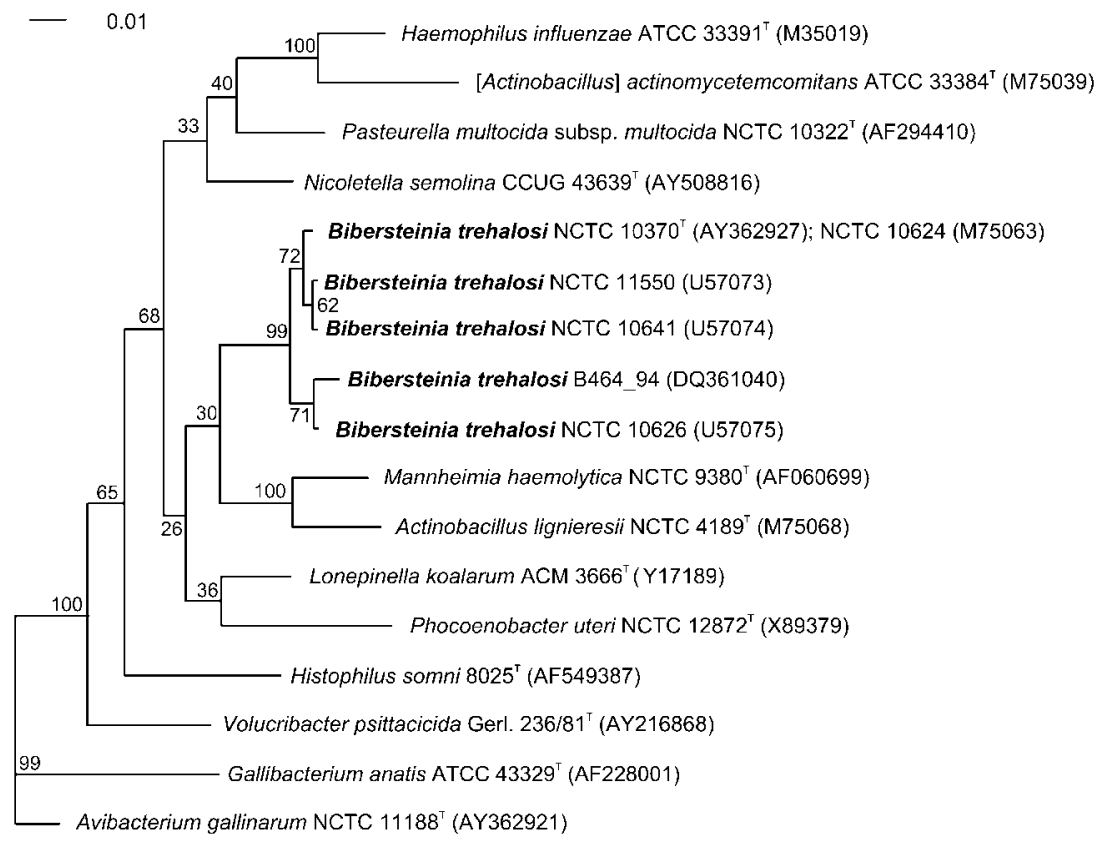

Fig. 2. Phylogenetic relationships based upon maximum-likelihood analysis of 16S rRNA gene sequences of members of the genus Bibersteinia gen. nov. and members of representative genera in the family Pasteurellaceae. Support for specified nodes obtained in bootstrap analysis is indicated. Strains sequenced in the present study are shown in bold. Bar, 0.01 evolutionary distance.

propose that $[P$.$] trehalosi should be housed within a$ separate genus, for which we propose the name Bibersteinia gen. nov.

At the genus level, the genus Bibersteinia is clearly phenotypically distinguishable from all other genera in the family Pasteurellaceae (Table 2). The genus Bibersteinia can be separated from the existing genera of Pasteurellaceae by the following characteristics: catalase, porphyrin test, urease, indole production, phosphatase, $\alpha$-glucosidase and production of acid without gas from dulcitol, $(+)$-D-galactose, (+)-D-mannose, (+)-D-trehalose and glycosides.

AFLP was used in this study to assess diversity within Bibersteinia ([Pasteurella]) trehalosi. The collection of strains used in our study was as diverse as we could assemble, representing four host species (bovine, caprine, cervine and ovine) and four countries (Belgium, Denmark, Sweden and the UK). Despite this diversity, the AFLP patterns all showed a similarity of at least $70 \%$. The only strains in this study that shared less than $55 \%$ similarity in AFLP profiles with the 43 Bibersteinia ([Pasteurella]) trehalosi strains were all members of other taxa (one unidentified strain, one $P$. multocida strain and one M. varigena strain). The clusters recognized by AFLP did show some association with host species; only one of the five multi-member clusters included isolates from more than one host species. The examination of more isolates, including from geographical regions not covered in this study, is necessary to determine whether there is an association between clonal lines of Bibersteinia ([Pasteurella]) trehalosi and host species.

Most standard texts refer to the fact that Bibersteinia ([Pasteurella]) trehalosi is a pathogen of sheep and do not mention any role in bovine disease, e.g. Gilmour \& Gilmour
(1989). In our study, 14 of 43 strains of Bibersteinia ([Pasteurella]) trehalosi were isolated from cattle. As this was a retrospective study, detailed case histories were not available for these bovine isolates. However, the fact that three Bibersteinia ([Pasteurella]) trehalosi strains were associated with granulomas (strains C1019-II, 1009-1 and C1008-I) and one (B96/39) was obtained from a joint suggests at least the possibility that these bovine strains may have a role in pathogenic processes. Most of the bovine isolates of Bibersteinia ([Pasteurella]) trehalosi (nine strains) were isolated from the respiratory tract and it is difficult to assess their role as primary pathogens. While Bibersteinia ([Pasteurella]) trehalosi does not appear to have been commonly reported from cattle, the organism was found to be the most common member of the family Pasteurellaceae to be cultured from the tonsils of commercially reared American bison (Bison bison) (Ward et al., 1999). The past tendency to lump field isolates within the '[Pasteurella] haemolytica' complex may have obscured the role of Bibersteinia ([Pasteurella]) trehalosi in bovine disease. Our study, plus the comprehensive description of the genus Mannheimia with five species, M. haemolytica, M. glucosida, M. granulomatis, $M$. ruminalis and $M$. varigena (Angen et al., 1999), now allows diagnostic laboratories to effectively and accurately identify quite distinct taxa that would have once been simply called '[Pasteurella] haemolytica'. Thorough identification of all Pasteurellaceae-like organisms should be undertaken where possible.

Of the 43 Bibersteinia ([Pasteurella]) trehalosi strains examined in this study, 22 strains, all of ovine origin, showed haemolytic activity (albeit weak haemolysis) against bovine red blood cells. All 14 bovine isolates, the sole caprine isolate and the three cervine isolates failed to show haemolytic activity. This pattern was essentially repeated with the 
Table 2. Key characteristics for the differentiation of genera within the family Pasteurellaceae

Genera: 1, Actinobacillus sensu stricto; 2, Pasteurella sensu stricto; 3, Haemophilus sensu stricto (includes H. influenzae, H. haemolyticus and H. aegypticus; results for $H$. parainfluenzae and $H$. pittmania are given in [ ]); 4, Mannheimia; 5, Lonepinella; 6, Phocoenobacter; 7, Gallibacterium; 8, Volucribacter; 9, Histophilus; 10, Avibacterium; 11, Nicoletella; 12, Bibersteinia gen. nov. Data are based on Angen et al. (1999, 2003), Bisgaard \& Mutters (1986), Blackall et al. (2005), Christensen \& Bisgaard (2003, 2004), Christensen et al. (2003a, b, 2004a, b), Kuhnert et al. (2004), Mutters et al. (1985) and this study. +, $90 \%$ or more of the strains positive within 1-2 days; $(+)$, $90 \%$ or more of the strains positive within 3-14 days; -, less than $10 \%$ of the strains are positive within 14 days; D, 11-89\% of the strains are positive; W, weakly positive.

\begin{tabular}{|c|c|c|c|c|c|c|c|c|c|c|c|c|}
\hline Characteristic & 1 & 2 & 3 & 4 & 5 & 6 & 7 & 8 & 9 & 10 & 11 & 12 \\
\hline Catalase & D & D & D & D & - & - & + & D & - & D & + & D \\
\hline NAD requirement & $-{ }^{\star}$ & $-\dagger$ & $+[\mathrm{D}]$ & - & - & - & - & - & - & $+\ddagger$ & - & - \\
\hline Porphyrin & + & + & $-[+]$ & + & + & + & + & + & - & + & ND & + \\
\hline Methyl red & - & - & $\mathrm{ND}$ & - & - & ND & $\mathrm{W}$ & + & ND & - & ND & - \\
\hline Voges-Proskauer & - & - & ND & - & $\mathrm{D}$ & + & - & - & - & - & ND & - \\
\hline Urease & + & $-\S$ & $+[\mathrm{D}]$ & - & - & - & - & - & - & - & + & - \\
\hline Indole & - & + & $\mathrm{D}$ & - & - & - & - & - & + & - & - & - \\
\hline Phosphatase & + & + & + & + & - & + & + & $+/ \mathrm{w}$ & + & +11 & $\mathrm{D}$ & + \\
\hline Pigment & - & - & ND & - & - & ND & - & - & + & $\mathrm{D}$ & ND & $\mathrm{D}$ \\
\hline \multicolumn{13}{|l|}{ Acid from: } \\
\hline (-)-D-Arabinose & - & $\mathrm{D}$ & ND & $\mathrm{D}$ & $(+)$ & ND & $(+)$ & - & ND & $\mathrm{D}$ & ND & - \\
\hline Dulcitol & - & $\mathrm{D}$ & - & - & + & - & - & - & ND & - & - & - \\
\hline (-)-D-Mannitol & +9 & $\mathrm{D}$ & - & + & - & - & + & - & $\mathrm{ND}$ & $\mathrm{D}$ & - & + \\
\hline (-)-D-Fructose & + & + & $-[\mathrm{D}]$ & + & + & ND & + & + & - & + & - & + \\
\hline$(+)$-D-Galactose & $\mathrm{D}$ & + & + & + & $\mathrm{ND}$ & ND & + & + & $\mathrm{ND}$ & $\mathrm{D}$ & - & - \\
\hline$(+)$-D-Mannose & $\mathrm{D}$ & + & $-[+]$ & - & + & - & + & + & $\mathrm{ND}$ & + & - & + \\
\hline Maltose & + & - & + & $\mathrm{D}$ & + & - & $\mathrm{D}$ & $\mathrm{D}$ & - & $\mathrm{D}$ & - & + \\
\hline Sucrose & + & + & $-[\mathrm{D}]$ & + & $\mathrm{D}$ & - & + & + & - & + & - & + \\
\hline$(+)$-D-Trehalose & $\mathrm{D}$ & $\mathrm{D}$ & - & - & - & - & $\mathrm{D}$ & - & - & $\mathrm{D}$ & - & + \\
\hline Glycosides & $\mathrm{D}$ & - & - & $\mathrm{D}$ & + & $\mathrm{D}$ & - & - & ND & - & ND & $\mathrm{D}$ \\
\hline ONPG & $\mathrm{D}$ & $\mathrm{D}$ & $-[\mathrm{D}]$ & $\mathrm{D}$ & + & + & + & $\mathrm{D}$ & ND & $\mathrm{D}$ & $\mathrm{D}$ & - \\
\hline$\alpha$-Glucosidase & $\mathrm{D}$ & + & - & - & - & ND & + & - & ND & + & ND & $\mathrm{D}$ \\
\hline$\beta$-Glucuronidase & - & - & - & - & + & ND & - & - & ND & - & ND & - \\
\hline
\end{tabular}

Discrepant results are indicated by: ${ }^{\star}$ Actinobacillus pleuropneumoniae biovar 1 is positive; $\dagger$. multocida might be positive; $\ddagger$ Avibacterium gallinarum is negative; some isolates of Avibacterium paragallinarum are also negative (biovar 2); \$Pasteurella dagmatis is positive; ॥Avibacterium paragallinarum biovar 1 might be negative; Actinobacillus suis is negative.

CAMP test; all 22 ovine strains were positive while the only other strains to be positive in the CAMP test were two bovine isolates. We explored the use of the PCR developed by Green et al. (1999) for the identification of the leukotoxin gene in Bibersteinia ([Pasteurella]) trehalosi. While we did not examine the full set of isolates, we found that the ten haemolytic and CAMP-positive strains (all ovine in origin) were clearly positive in this PCR, while five non-haemolytic and CAMP-negative isolates (four bovine and one cervine) gave a weak positive reaction. As the haemolytic activity of Bibersteinia ([Pasteurella]) trehalosi has been reported to correlate with the production of leukotoxin (Ward et al., 1999), our finding that the haemolytic and CAMP-positive strains were all clearly positive in the leukotoxin PCR was an expected finding. The finding that the non-haemolytic and CAMP-negative isolates gave an unclear result (weak positive) was not expected. The initial development and validation of the leukotoxin PCR by Green et al. (1999) noted that the test was highly reproducible. Green et al. (1999) used isolates from bighorn sheep and reported clear cut results with a correlation between a positive PCR result and the ability to produce cytotoxic effects in vitro. The difficulties we have encountered suggest that further detailed studies using isolates from both domestic and wild ruminants are necessary before a full understanding of the means of detecting the leukotoxin gene is reached. This requirement for further study on isolates from domestic ruminants was noted by Green et al. (1999) and is still a relevant cautionary note.

\section{Description of Bibersteinia gen. nov.}

Bibersteinia (Bi.ber.stei'ni.a. N.L. fem. n. Bibersteinia bacterial genus named after Ernst L. Biberstein, who did much of the early characterization work on this organism, including the creation of the serotyping scheme and some of the 
earliest DNA-DNA relatedness studies that indicated the unique nature of this taxon).

A member of the family Pasteurellaceae as defined by Olsen et al. (2005). Gram-negative, non-motile, rod-shaped or pleomorphic with cells occurring singly and in pairs or short chains depending upon the growth stage. Colonies on bovine blood agar are round, regular, greyish or yellowish, semi-transparent at the periphery and are about $2 \mathrm{~mm}$ in diameter after $24 \mathrm{~h}$ at $37^{\circ} \mathrm{C}$. Some isolates are haemolytic and are CAMP-positive. Endospores are not formed. Growth is mesophilic and facultatively anaerobic or microaerophilic. Nitrate is reduced without gas production. The reaction in Hugh-Leifson medium with (+)-D-glucose is fermentative without gas production. Porphyrin, phosphatase and alanine aminopeptidase tests are positive. Negative reactions occur for Simmons' citrate, malonate-base, growth in the presence of KCN, Voges-Proskauer, methyl red and urease tests. Negative tests are further observed with ONPG, arginine dehydrolase, lysine decarboxylase, ornithine decarboxylase, phenylalanine deaminase, indole, gelatinase and hydrolysis of Tweens 20 and 80 . Acid is formed from (-)-Dribose, (-)-D-mannitol, (-)-D-sorbitol, (-)-D-fructose, $(+)$-D-glucose, $(+)$-D-mannose, maltose, sucrose, $(+)$-Dtrehalose and dextrin. Acid is not produced from adonitol, $(+)$-D-arabitol, (-)-D-arabinose, (+)-L-arabinose, myoerythritol, dulcitol, (+)-D-fucose, (-)-L-fucose, $(+)$-Dgalactose, D-glycogen, inulin, lactose, $(+)$-D-melibiose, $(+)$-D-melezitose, $(+)$-L-rhamnose, $(-)$-L-sorbose, $(+)$ D-turanose, xylitol, $(+)$-D-xylose or (-)-L-xylose. Reactions for $\alpha$-fucosidase, $\alpha$-galactosidase $\beta$-galactosidase, $\beta$-glucuronidase (PGUA), $\alpha$-mannosidase and $\beta$-xylosidase are negative. Variable reactions occur for the catalase and oxidase tests and the production of acid from glycerol, myoinositol, cellobiose, raffinose, aesculin, amygdalin, arbutin, gentiobiose and salicin. Variable reactions are also obtained in the $\alpha$-glucosidase and $\beta$-glucosidase tests.

The DNA G $+\mathrm{C}$ content is reported as $42.6 \mathrm{~mol} \%$ (Mutters et al., 1985, 1986). The type species of the genus is Bibersteinia trehalosi, originally described as [Pasteurella] trehalosi by Sneath \& Stevens (1990).

\section{Description of Bibersteinia trehalosi comb. nov.}

Basonym: Pasteurella trehalosi Sneath \& Stevens 1990.

Key tests that allow the separation of Bibersteinia trehalosi from the other genera of the Pasteurellaceae are shown in Table 2. For characteristics showing variation in Table 2, the type strain shows the following reactions: catalase and oxidase-negative, weak haemolysis on bovine blood agar, CAMP-positive, weak growth on MacConkey agar, yellowish pigment, production of acid from cellobiose, raffinose, aesculin, amygdalin, arbutin, gentiobiose and salicin, no acid production from glycerol and myo-inositol. The type strain is NCTC $10370^{\mathrm{T}}\left(=\right.$ ATCC $\left.29703^{\mathrm{T}}\right)$.

\section{Acknowledgements}

We would like to thank Professor Dr Hans G. Trüper, Rheinische Friedrich-Wilhelms-Universität, Bonn, for help with the Latin name.

\section{References}

Adlam, C. (1989). The structure, function and properties of cellular and extracellular components of Pasteurella haemolytica. In Pasteurella and Pasteurellosis, pp. 75-92. Edited by C. F. Adlam \& J. M. Rutter. London: Academic Press.

Altschul, S. F., Madden, T. L., Schaffer, A. A., Zhang, J., Zhang, Z., Miller, W. \& Lipman, D. J. (1997). Gapped BLAST and PSI-BLAST: a new generation of protein database search programs. Nucleic Acids Res 25, 3389-3402.

Angen, O., Mutters, R., Caugant, D. A., Olsen, J. E. \& Bisgaard, M. (1999). Taxonomic relationships of the [Pasteurella] haemolytica complex as evaluated by DNA-DNA hybridizations and 16S rRNA sequencing with the proposal of Mannheimia haemolytica gen. nov., comb. nov., Mannheimia granulomatis comb. nov., Mannheimia glucosida sp. nov., Mannheimia ruminalis sp. nov. and Mannheimia varigena sp. nov. Int J Syst Bacteriol 49, 67-86.

Angen, O., Ahrens, P., Kuhnert, P., Christensen, H. \& Mutters, R. (2003). Proposal of Histophilus somni gen. nov., sp. nov. for the three species incertae sedis 'Haemophilus somnus', 'Haemophilus agni' and 'Histophilus ovis'. Int J Syst Evol Microbiol 53, 1449-1456.

Applied Biosystems (2000). Automated DNA Sequencing Chemistry Guide, 264 pp. Foster City, CA: Applied Biosystems.

Benson, D. A., Karsch-Mizrachi, I., Lipman, D. J., Ostell, J. \& Wheeler, D. L. (2004). GenBank: update. Nucleic Acids Res 32 (Database issue), D23-26.

Biberstein, E. L. \& Francis, C. K. (1968). Nucleic acid homologies between the $\mathrm{A}$ and $\mathrm{T}$ types of Pasteurella haemolytica. J Med Microbiol 1, 105-108.

Biberstein, E. L., Gills, M. \& Knight, H. (1960). Serological types of Pasteurella haemolytica. Cornell Vet 50, 283-300.

Bisgaard, M. \& Mutters, R. (1986). Characterization of some previously unclassified "Pasteurella" spp. obtained from the oral cavity of dogs and cats and description of a new species tentatively classified with the family Pasteurellaceae Pohl 1981 and provisionally called taxon 16. Acta Pathol Microbiol Immunol Scand [B] 94, 177-184.

Bisgaard, M., Houghton, S. B., Mutters, R. \& Stenzel, A. (1991). Reclassification of German, British and Dutch isolates of so-called Pasteurella multocida obtained from pneumonic calf lungs. Vet Microbiol 26, 115-124.

Blackall, P. J., Angen, O., Fegan, N., Blackall, L. L., Mutters, R. \& Bisgaard, M. (2001). Characterisation of a novel Mannheimia sp from Australian feedlot cattle. Aust Vet J 79, 634-639.

Blackall, P. J., Christensen, H., Beckenham, T., Blackall, L. L. \& Bisgaard, M. (2005). Reclassification of Pasteurella gallinarum, [Haemophilus] paragallinarum, Pasteurella avium and Pasteurella volantium as Avibacterium gallinarum gen. nov., comb. nov., Avibacterium paragallinarum comb. nov., Avibacterium avium comb. nov. and Avibacterium volantium comb. nov. Int J Syst Evol Microbiol 55, 353-362.

Busse, H. J., Bunka, S., Hensel, A. \& Lubitz, W. (1997). Discrimination of members of the family Pasteurellaceae based on polyamine patterns. Int J Syst Bacteriol 47, 698-708.

Christensen, H. \& Bisgaard, M. (2003). The genus Pasteurella. In The Prokaryotes. Edited by M. Dworkin. New York: Springer. 
Christensen, H. \& Bisgaard, M. (2004). Revised definition of Actinobacillus sensu stricto isolated from animals: A review with special emphasis on diagnosis. Vet Microbiol 99, 13-30.

Christensen, H., Bisgaard, M., Bojesen, A. M., Mutters, R. \& Olsen, J. E. (2003a). Genetic relationships among avian isolates classified as Pasteurella haemolytica, 'Actinobacillus salpingitidis' or Pasteurella anatis with proposal of Gallibacterium anatis gen. nov., comb. nov. and description of additional genomospecies within Gallibacterium gen. nov. Int J Syst Evol Microbiol 53, 275-287.

Christensen, H., Foster, G., Christensen, J. P., Pennycott, T., Olsen, J. E. \& Bisgaard, M. (2003b). Phylogenetic analysis by $16 \mathrm{~S}$ rDNA gene sequence comparison of avian taxa of Bisgaard and characterization and description of two new taxa of Pasteurellaceae. J Appl Microbiol 95, 354-363.

Christensen, H., Bisgaard, M., Aalbaek, B. \& Olsen, J. E. (2004a). Reclassification of Bisgaard taxon 33, with proposal of Volucribacter psittacicida gen. nov., sp. nov. and Volucribacter amazonae sp. nov. as new members of the Pasteurellaceae. Int J Syst Evol Microbiol 54, 813-818.

Christensen, H., Angen, O., Olsen, J. E. \& Bisgaard, M. (2004b). Revised description and classification of atypical isolates of Pasteurella multocida from bovine lungs based on genotypic characterization to include variants previously classified as biovar 2 of Pasteurella canis and Pasteurella avium. Microbiology 150, 1757-1767.

Christensen, H., Kuhnert, P., Olsen, J. E. \& Bisgaard, M. (2004c). Comparative phylogenies of the housekeeping genes atpD, inf $B$ and $r p o B$ and the 16S rRNA gene within the Pasteurellaceae. Int J Syst Evol Microbiol 54, 1601-1609.

Christie, R., Atkins, N. E. \& Munch-Petersen, E. (1944). A note on a lytic phenomenon shown by group B streptococci. Aust J Exp Biol Med Sci 22, 197-200.

Davies, R. L. \& Quirie, M. (1996). Intra-specific diversity within Pasteurella trehalosi based on variation of capsular polysaccharide, lipopolysaccharide and outer-membrane proteins. Microbiology 142, 551-560.

Davies, R. L., Paster, B. J. \& Dewhirst, F. E. (1996). Phylogenetic relationships and diversity within the Pasteurella haemolytica complex based on 16S rRNA sequence comparison and outer membrane protein and lipopolysaccharide analysis. Int J Syst Bacteriol 46, 736-744.

Davies, R. L., Arkinsaw, S. \& Selander, R. K. (1997). Genetic relationships among Pasteurella trehalosi isolates based on multilocus enzyme electrophoresis. Microbiology 143, 2841-2849.

De Ley, J., Mannheim, W., Mutters, R., Piechulla, K., Tytgat, R., Segers, P., Bisgaard, M., Frederiksen, W., Hinz, K. H. \& Vanhoucke, M. (1990). Inter- and intrafamilial similarities of rRNA cistrons of the Pasteurellaceae. Int J Syst Bacteriol 40, 126-137.

Dewhirst, F. E., Paster, B. J. \& Bright, P. L. (1989). Chromobacterium, Eikenella, Kingella, Neisseria, Simonsiella, and Vitreoscilla species comprise a major branch of the beta group Proteobacteria by $16 \mathrm{~S}$ ribosomal ribonucleic acid sequence comparison: transfer of Eikenella and Simonsiella to the family Neisseriaceae (emend.). Int $J$ Syst Bacteriol 39, 258-266.

Gilmour, N. J. L. \& Gilmour, J. S. (1989). Pasteurellosis of sheep. In Pasteurella and Pasteurellosis, pp. 223-261. Edited by C. F. Adlam \& J. M. Rutter. London: Academic Press.
Green, A. L., DuTeau, N. M., Miller, M. W., Triantis, J. M. \& Salman, M. D. (1999). Polymerase chain reaction techniques for differentiating cytotoxic and noncytotoxic Pasteurella trehalosi from Rocky Mountain bighorn sheep. Am J Vet Res 60, 583-588.

Kuhnert, P., Korczak, B., Falsen, E., Straub, R., Hoops, A., Boerlin, P., Frey, J. \& Mutters, R. (2004). Nicoletella semolina gen. nov., sp. nov., a new member of Pasteurellaceae isolated from horses with airway disease. J Clin Microbiol 42, 5542-5548.

Leisner, J. J., Pot, B., Christensen, H., Rusul, G., Olsen, J. E., Wee, B. W., Muhamad, K. \& Ghazali, H. M. (1999). Identification of lactic acid bacteria from chili bo, a Malaysian food ingredient. Appl Environ Microbiol 65, 599-605.

Mutters, R., Ihm, P., Pohl, S., Frederiksen, W. \& Mannheim, W. (1985). Reclassification of the genus Pasteurella Trevisan 1887 on the basis of deoxyribonucleic acid homology, with proposals for the new species Pasteurella dagmatis, Pasteurella canis, Pasteurella stomatis, Pasteurella anatis, and Pasteurella langaa. Int J Syst Bacteriol 35, 309-322.

Mutters, R., Bisgaard, M. \& Pohl, S. (1986). Taxonomic relationships of selected biogroups of Pasteurella haemolytica as revealed by DNA:DNA hybridizations. Acta Pathol Microbiol Immunol Scand [B] 94, 195-202.

Olsen, G. J., Matsuda, H., Hagstrom, R. \& Overbeek, R. (1994). FastDNAml: a tool for construction of phylogenetic trees of DNA sequences using maximum likelihood. Comput Appl Biosci 10, 41-48.

Olsen, I., Dewhirst, F. E., Paster, B. J. \& Busse, H.-J. (2005). Family Pasteurellaceae. In Bergey's Manual of Systematic Bacteriology, 2nd edn, vol 2, part 2, pp. 851-856. Edited by D. J. Brenner, N. R. Kreig \& J. T. Staley. New York: Springer.

Paster, B. J. \& Dewhirst, F. E. (1988). Phylogeny of campylobacters, wolinellas, Bacteroides gracilis, and Bacteroides ureolyticus by $16 \mathrm{~S}$ ribosomal ribonucleic acid sequencing. Int J Syst Bacteriol 38, 56-62.

Pohl, S. (1981). DNA relatedness among members of Haemophilus, Pasteurella and Actinobacillus. In Haemophilus, Pasteurella and Actinobacillus, pp. 245-253. Edited by M. Kilian, W. Frederiksen \& E. L. Biberstein. London: Academic Press.

Rice, P., Longden, I. \& Bleasby, A. (2000). EMBOSs: the European Molecular Biology Open Software Suite. Trends Genet 16, 276-277.

Smith, G. R. (1959). Isolation of two types of Pasteurella haemolytica from sheep. Nature 183, 1132-1133.

Sneath, P. H. \& Stevens, M. (1990). Actinobacillus rossii sp. nov., Actinobacillus seminis sp. nov., nom. rev., Pasteurella bettii sp. nov., Pasteurella lymphangitidis sp. nov., Pasteurella mairi sp. nov., and Pasteurella trehalosi sp. nov. Int J Syst Bacteriol 40, 148-153.

Thompson, J. D., Gibson, T. J., Plewniak, F., Jeanmougin, F. \& Higgins, D. G. (1997). The CLUSTAL_X windows interface: flexible strategies for multiple sequence alignment aided by quality analysis tools. Nucleic Acids Res 25, 4876-4882.

Vogel, B. F., Jorgensen, K., Christensen, H., Olsen, J. E. \& Gram, L. (1997). Differentiation of Shewanella putrefaciens and Shewanella alga on the basis of whole-cell protein profiles, ribotyping, phenotypic characterization, and $16 \mathrm{~S}$ rRNA gene sequence analysis. Appl Environ Microbiol 63, 2189-2199.

Ward, A. C., Dyer, N. W. \& Fenwick, B. W. (1999). Pasteurellaceae isolated from tonsillar samples of commercially-reared American bison (Bison bison). Can J Vet Res 63, 161-165. 